\title{
Nutritional Status of Female Adolescents and Early Adults in Aseer Region, Abha District
}

\author{
Vedavalli Sachithananthan ${ }^{*}$ and Nusreth Jehan
}

Faculty of Public Health, College of Applied Medical Sciences, King Khalid University, Abha, Saudi Arabia

\begin{abstract}
The nutritional status of adolescents and early adults is 'at risk' because of the booming up of the fast food industry and decline in physical activity. An attempt was made in this study to understand the nutritional status of female adolescents and early adults in Aseer region of Abha district. Using a structured and validated questionnaire, the age, height, weight, waist circumference, hip circumference income and education of parents and physical activity were assessed. The anthropometric profile (Mean) indicates that almost all parameters were within normal range. However 36.6 percent of the subjects fell in the 'at risk' category of waist hip ratio. With respect to the body mass index, a majority of the subjects were normal weight $(68.3 \%)$, followed by 16.8 percent who were overweight and 14.9 percent underweight. In conclusion it can be stated that the overweight and underweight subjects should be brought to the normal weight category by consuming a nutritionally balanced diet and adequate physical activity to prevent malnutrition problems and chronic diseases for the underweight and overweight adolescents and early adults in the long run.
\end{abstract}

Keywords: Nutritional status, female adolescents, early adults, balanced diet.

\section{INTRODUCTION}

Adolescents are those between the ages of 10 and 19 years old [1] and adolescence is a transitional phase between childhood and adulthood characterized by marked acceleration in growth [2, 3]. This period is known to be a second chance for growth or catch-up growth for those children who have experienced a nutritional deficit in their early life $[4,5]$. It is a period of increased nutritional requirements because it is during this time that they gain up to $50 \%$ of their adult height and skeletal mass [1].

Adolescence is a phase that poses specific challenges for treating diseases and promoting health [6]. Recent reports of the World Health Organization (WHO) suggest that in South East Asian Region a large number of adolescents, who constitute $20 \%$ of the population in these countries, suffer from malnutrition and anemia, which adversely impacts their health and development [2] and that anthropometry is a good indicator of nutritional status and health risks (namely overweight or obesity) in this group [3, 7]. Several factors affect the nutritional status of adolescents. Among these, socio-economic and demographic factors are associated with worldwide patterns of stunting and thinness.

\section{MATERIALS AND METHODS}

The Aseer region of Abha district was selected for the study due to ease of accessibility. Out of 25

${ }^{*}$ Address correspondence to this author at the Faculty of Public Health, College of Applied Medical Sciences, King Khalid University, Abha, Saudi Arabia;

E-mail: dr_vedavalli@yahoo.com schools available, five schools and out of 2 colleges one college was randomly selected for the study. 500 girls $16-18$ years of age and 18 to 20 years of age were randomly selected for the assessments from schools and colleges respectively.

Family background details to include education of the parents and parental income were collected using a questionnaire. Height, weight (calculation of Body mass index) using standard equipment, waist circumference and hip circumference using an inch tape were measured and waist hip ratio was computed.

Body mass index formula $=$ Weight $/$ Height $^{2}$ in metres [8]

Weight hip ratio $=$ Waist circumference/Hip circumference [9]

Upto 30 minutes of brisk walking was categorized under physical activity and this was measured.

A food frequency questionnaire was framed and validated to collect details on the frequency of food consumption of the subjects. For example, the table of food frequency will contain data on different food groups and consecutive columns will contain data on whether the foods were consumed daily, weekly, fortnightly, monthly or rarely. Data was collected after informed consent from the subjects and the ethical committee approval of King Khalid university.

\section{RESULTS AND DISCUSSION}

A majority of subjects hailed from a family with income of 15001 to 20000 Saudi riyals (SR) per month, 
followed by 22.8 percent with an income of 15001 to 20000 SR. A minimum of 7.9 percent of the families had a monthly income of greater than 25000 SR per month.

Table 1: Family Income of the Selected Subjects

\begin{tabular}{|c|c|}
\hline Category of income (Saudi riyals) & \% of subjects \\
\hline \hline $5000-10000$ & 17.8 \\
\hline $10001-15000$ & 33.7 \\
\hline $15001-20000$ & 22.8 \\
\hline $20001-25000$ & 17.8 \\
\hline$>25000$ & 7.9 \\
\hline
\end{tabular}

$(1 \mathrm{SAR}=0.266 \mathrm{USD})$.

Out of the total, a majority of 44.6 percent of the fathers were educated up to school level and only around 3 percent of the fathers did not attend school. A majority of the mothers were also educated up to the school level (57.4\%), while only 6.9 percent did not attend school.

Table 2:

\begin{tabular}{|c|c|c|}
\hline Category & Mean & $\begin{array}{c}\text { Standard } \\
\text { deviation }\end{array}$ \\
\hline \hline Age (years) & 17.9 & 1.318 \\
\hline Height (metres) & 1.58 & 0.788 \\
\hline Weight $(\mathrm{kg})$ & 54.3 & 11.052 \\
\hline Waist circumference $(\mathrm{cm})$ & 73.3 & 10.377 \\
\hline Hip circumference $(\mathrm{cm})$ & 93.7 & 11.44 \\
\hline Body mass index & 21.7 & 3.36 \\
\hline Waist Hip ratio & 0.79 & 0.09 \\
\hline
\end{tabular}

The mean age in years of the selected subjects was 17.9. The height and weight of the subjects were 1.58 metres and $54.3 \mathrm{~kg}$ respectively. The body mass index was 21.7 which represented subjects with normal weight for height. The waist circumference and hip circumference were $73.3 \mathrm{~cm}$ and $93.7 \mathrm{~cm}$ respectively and the waist to hip ratio was 0.79 . The anthropometric profile indicates that almost all parameters (Mean) were within normal range.

The normal waist to hip ratio for women and men were 0.8 to 0.9 respectively. A waist to hip ratio of $>1$ is considered to be at risk (73). A majority of subjects $(63.4 \%)$ fell under the normal category of waist hip ratio. Less than $36.6 \%$ were in the "at risk" category with respect to waist hip ratio.
Table 3: Body Mass Index (BMI) of the Selected Subjects

\begin{tabular}{|c|c|}
\hline BMI category & \% of subjects \\
\hline \hline Underweight & 14.9 \\
\hline Normal & 68.3 \\
\hline Overweight & 16.8 \\
\hline
\end{tabular}

A majority of the subjects were of normal weight (68.3\%), followed by 16.8 percent who were overweight and 14.9 percent underweight. This may be due to the fact that the normal waist to hip ratio for women and men were 0.8 and 0.9 respectively. A waist to hip ratio of $>1$ is considered to be at risk (73). A majority of subjects $(63.4 \%)$ fell under the normal category of waist hip ratio. Less than $36.6 \%$ were in the "at risk" category with respect to waist hip ratio.

\section{DISCUSSION}

A positive correlation existed between family income and education of the parents. The mean waist circumference, hip circumference and waist hip ratio were in the normal range. The BMl is normal in a majority of subjects. A positive correlation existed between BMI and waist hip ratio. This category of adolescents and adults who were overweight should be followed up for weight reduction and those who were underweight and malnourished should be given a balanced diet.

\section{CONCLUSION}

Many chronic diseases may affect this adolescent and early adult population and hence urgent measures should be undertaken to bring this category of underweight adolescents and early adults to normal weight category through a balanced diet and adequate physical activity.

\section{REFERENCES}

[1] World Health Organization Physical Status: The use and Interpretation of Anthropometry Technical Report Series 854 Geneva. World Health Organization 1995; 263-308.

[2] Adolescents Nutrition: A review of the situation is selected South - East Asian countries World Health Organization. Regional office of South East Asia. 2005. Dec 29, Executive Summary.

[3] Anand K, Kant S, Kapoor SK. Nutritional Status of Adolescents school children in rural north India. Indian Pediatr 1999; 36: 810-5.

[4] Rao S. Nutritional Status of Indian population. J Biosci 2001; 26: 481-9.

[5] Delisle H, Mauli VC, De Benoist B. Should Adolescents be specifically targeted for nutrition in developing countries? To 
address which problems and how? Available from: http://www.who.int/child-adolescent. [last accessed on 2005 Jul 10]

[6] Christie D, Viner R. Adolescents development (ABC of Adolescents) BMJ 2005; 330(7486): 301-4.

[7] Takhor HG, Kumar P, Desai VK, Srivastara RK. Physical growth standards of Urban Adolescents (10-15) years from south Gujarat. Indian J Community Med 2000-04 2000; 6: $25-2$.
[8] Centers for disease control and prevention - Body Mass Index. Available online at www.cdc.gov/healthy weight/assessing/bmi/adult_bmi/. Accessed on 21/04/2015

[9] Waist to hip ratio (WHR). Available online at http//www.topendsports.com/testing/tests/WHR.htm.

Avvessed on 21/04/2015. 